\title{
Calcium channel a $\delta 1$ subunit is a functional marker and therapeutic target for tumor-initiating cells in non-small cell lung cancer
}

\author{
Yuanyuan $\mathrm{Ma}^{1}$, Xiaodan Yang ${ }^{2}$, Wei Zhao $\mathbb{D}^{2}$, Yue Yang ${ }^{1}$ and Zhiqian Zhang $\mathbb{1}^{2}$
}

\begin{abstract}
It is hypothesized that tumor-initiating cells (TICS) with stem cell-like properties constitute a sustaining force to drive tumor growth and renew fully established malignancy. However, the identification of such a population in non-small cell lung carcinoma (NSCLC) has been hindered by the lacking of reliable surface markers, and very few of the currently available surface markers are of functional significance. Here, we demonstrate that a subpopulation of TICs could be specifically defined by the voltage-gated calcium channel a2 $\delta 1$ subunit from non-small cell lung carcinoma (NSCLC) cell lines and clinical specimens. The $a 2 \delta 1^{+}$NSCLC TICS are refractory to conventional chemotherapy, and own stem cell-like properties such as self-renewal, and the ability to generate heterogeneous tumors in NOD/SCID mice. Moreover, a $281^{+}$NSCLC cells are more enriched for TICs than $\mathrm{CD}_{133^{+}}$, or $\mathrm{CD}_{166^{+}}$cells. Interestingly, a $2 \delta 1$ is functionally sufficient and indispensable to promote TIC properties by mediating $\mathrm{Ca}^{2+}$ influx into cells, which subsequently activate Calcineurin/NFATC2 signaling that directly activates the expression of NOTCH3, ABCG2. Importantly, a specific antibody against a $2 \delta 1$ has remarkably therapeutic effects on NSCLC xenografts by eradicating TICs. Hence, targeting a $2 \delta 1$ to prevent calcium influx provides a novel strategy for targeted therapy against TICs of NSCLC.
\end{abstract}

\section{Introduction}

Non-small cell lung cancer (NSCLC) represents $\sim 85 \%$ of lung cancer, which is the leading cause of cancer-related mortality worldwide ${ }^{1}$. Despite aggressive frontline treatments including the use of target-specific small-molecule inhibitors, the prognosis of NSCLC is poor for most patients mainly due to its heterogenic nature, highly invasive potential and therapeutic resistance ${ }^{1,2}$. Tumorinitiating cells (TICs) are a subpopulation within a tumor that own stem cell-like properties such as self-renewal,

\footnotetext{
Correspondence: Yue Yang (zlyangyue@bjmu.edu.cn) or

Zhiqian Zhang (zlzqzhang@bjmu.edu.cn)

'Department of Thoracic Surgery Unit II, Laboratory of Carcinogenesis and

Translational Research (Ministry of Education/Beijing), Peking University Cancer Hospital and Institute, 52 Fucheng Road, Beijing 100142, China

${ }^{2}$ Department of Cell Biology, Key Laboratory of Carcinogenesis and Translational Research (Ministry of Education/Beijing), Peking University Cancer Hospital and Institute, 52 Fucheng Road, Beijing 100142, China These authors contributed equally: Yuanyuan Ma, Xiaodan Yang. Edited by G. Ciliberto
}

differentiation and strong tumorigenic capacity ${ }^{3,4}$. These cells have the ability to give rise to the heterogeneous lineages of cancer cells that comprise the tumor, and hence are proposed to constitute a sustaining force to drive and maintain fully malignancy ${ }^{5,6}$. Therapeutic approaches targeting TICs may therefore provide promising strategies to improve the outcome of cancer therapy, including that of $\mathrm{NSCLC}^{7}$. In NSCLC, TICs have been isolated with markers such as $\mathrm{CD} 133^{8}$, $\mathrm{CD} 44^{9}$, or $\mathrm{CD} 166^{10}$. However, some other studies have yielded conflicting results ${ }^{11,12}$, and very few of these markers are functionally linked to TIC properties. More robust markers that could be used for reliable identification of NSCLC TICs and preferentially serve as therapeutic targets are urgently needed.

We have previously identified that the isoform 5 of the voltage-gated calcium channel $\alpha 2 \delta 1$ subunit (encoded by the gene CACNA2D1), which is specifically recognized by the monoclonal antibody (mAb) 1B50-1, is a functional marker and therapeutic target for TICs of hepatocellular

\section{(c) The Author(s) 2021}

(c) (i) Open Access This article is licensed under a Creative Commons Attribution 4.0 International License, which permits use, sharing, adaptation, distribution and reproduction c. in any medium or format, as long as you give appropriate credit to the original author(s) and the source, provide a link to the Creative Commons license, and indicate if changes were made. The images or other third party material in this article are included in the article's Creative Commons license, unless indicated otherwise in a credit line to the material. If material is not included in the article's Creative Commons license and your intended use is not permitted by statutory regulation or exceeds the permitted use, you will need to obtain permission directly from the copyright holder. To view a copy of this license, visit http://creativecommons.org/licenses/by/4.0/. 
carcinoma and small cell lung cancer ${ }^{13,14}$. The expression of $\alpha 2 \delta 1$ results in calcium influx into cells, which subsequently determines the self-renewal, tumorigenic, survival and chemoresistance capabilities of $\mathrm{TICs}^{13-15} \cdot \alpha 2 \delta 1$ was known as an auxiliary subunit of voltage-gated calcium channel to mediate calcium influx into cells by functioning in both targeting and/or stabilization of the channel in the membrane and in shaping the specific gating properties of different channel isoforms including the channel-forming subunit $\alpha 1^{16,17}$, although the calcium-independent function of $\alpha 2 \delta 1$ was also appreciated in literature ${ }^{18}$. However, the calcium signaling pathways mediated by $\alpha 2 \delta 1$ in the determination of TIC properties remain elusive.

As a second messenger, elevated intracellular calcium ions $\left(\mathrm{Ca}^{2+}\right)$ result in the activation of calcium signaling, which regulates many cellular activities including cell migration, secretion, metabolism, and survival ${ }^{19,20}$. Among the key molecules involved in calcium signaling are the nuclear factor of activated $\mathrm{T}$ cells family members NFATc1, NFATc2, NFATc3, and NFATc4, which directly link calcium signaling to gene expression. They are located in the cytoplasm in a hyperphosphorylated state, and will subsequently translocate into nucleus to bind to the DNA-responsive elements (5'-GGAAA-3') in target gene promoters to regulate gene transcription when they are dephosphorylated by calcineurin ${ }^{21,22} \cdot \mathrm{Ca}^{2+}$ can activate Notch signaling pathway, a hallmark of TICs of many cancer types including NSCLC, and targeted therapy against Notch has been proved to suppress the TIC properties ${ }^{12,23-25}$, but how Notch signaling is activated in TICs is poorly understood.

Here, we show that $\alpha 2 \delta 1^{+}$cells of NSCLC own the stem cell-like properties, and represent a subset with the highest tumorigenic potential, compared with those defined by CD133, or CD166. Moreover, higher expression of $\alpha 2 \delta 1$ in cancer tissues was predictive of poor prognosis for patients with NSCLC. Interestingly, the expression of $\alpha 2 \delta 1$ is sufficient and necessary for the acquisition and subsequent maintenance of TIC properties via $\mathrm{Ca}^{2+}$-Calcineurin/ NFATc2-NOTCH3/ABCG2 signaling pathway. Importantly, mAb1B50-1 against $\alpha 2 \delta 1$ can selectively eradicate TICs, providing a novel approach of targeted therapy for NSCLC.

\section{Results}

Identification of $\alpha 2 \delta 1$ as a candidate for NSCLC TIC surface marker

In view of the fact that many of the TIC markers were overexpressed in tumor tissues ${ }^{10,26,27}$, we performed data mining in the TCGA transcriptome database to identify candidates for surface markers of NSCLC TICs, which were overexpressed in the cancer tissues of NSCLC. Compared with that in the normal tissues, the expression of CD24, CD90, EpCAM, CACNA2D1, and CD133 was found highly expressed in the cancer tissues (Fig. 1A). Flow cytometry results showed that the percentage of positive cells of the abovementioned molecules varied greatly across NSCLC cell lines including A549, H520, $\mathrm{H} 292$, H1299, PC9, H157, and GLC82, ranging from $<1 \%$ to almost $100 \%$ (Supplementary Table 1). We further tested the tumorigenic potential of fluorescence-activated cell sorting (FACS)-purified positive and negative populations of the abovementioned molecules from the lung adenocarcinoma cell line A549 by subcutaneously (s.c.) transplanting 1000 and 100 cells of each subset in Nonobese diabetic/severe combined immunodeficient (NODSCID) mice. Although all the $\mathrm{CD}^{+} 0^{+}, \mathrm{EpCAM}^{+}$, and $\alpha 2 \delta 1^{+}$A549 subpopulation showed higher tumorigenic capabilities than their negative counterparts, the TIC frequency of $\alpha 2 \delta 1^{+}$cells is the highest among these subpopulations tested (Fig. 1B, Supplementary Table 2). Hence, $\alpha 2 \delta 1$ was selected for further characterization as a potential TIC surface marker for NSCLC.

\section{Clinical significance of $a 2 \delta 1$ expression in NSCLC patients}

Consistently with its localization in cultured A549 cells, $\alpha 2 \delta 1$ localized in the cell membrane of $\alpha 2 \delta 1^{+}$cells, which were sparsely distributed in the cancer tissues as demonstrated by immunofluorescent staining (Fig. 1C). The expression of $\alpha 2 \delta 1$ mRNA in cancer tissues was significantly higher than that of matched normal tissues as detected in 83 paired NSCLC and adjacent normal tissues by quantitative reverse transcription-polymerase chain reaction (qRT-PCR) (Fig. 1D). Further analysis of the expression $\alpha 2 \delta 1$ mRNA in 169 cases of NSCLC tissues has revealed that the expression of $\alpha 2 \delta 1$ mRNA correlated positively with metastasis and advanced TNM stages of these patients, although it was not found significantly correlated with age, smoking history, gender, or venous invasion (Supplementary Table 3). Kaplan-Meier curves revealed that higher $\alpha 2 \delta 1$ expression in cancer tissues was significantly associated with shorter disease-free survival and overall survival of these NSCLC patients (Fig. 1E, F). Multivariate COX regression analysis also demonstrated that higher $\alpha 2 \delta 1$ mRNA level was an independent risk factor of unfavorable prognosis for these patients (Supplementary Table 4). The overexpression of $\alpha 2 \delta 1$ in NSCLC was also confirmed at the protein level by Western blot in 12 paired cancer and adjacent normal tissues (Fig. 1G).

\section{Confirmation of a $2 \delta 1$ as a TIC marker for NSCLC}

To verify that $\alpha 2 \delta 1$ indeed marks a population of TICs of NSCLC with stem cell-like properties, we sorted both the $\alpha 2 \delta 1^{+}$and $\alpha 2 \delta 1^{-}$subsets from the NSCLC cell lines A549, $\mathrm{H} 520$ and $\mathrm{H} 292$ using FACS to assay their spheroid-formation abilities in serum-free medium first. Purified $\alpha 2 \delta 1^{+}$cells were able to form spheres at much 


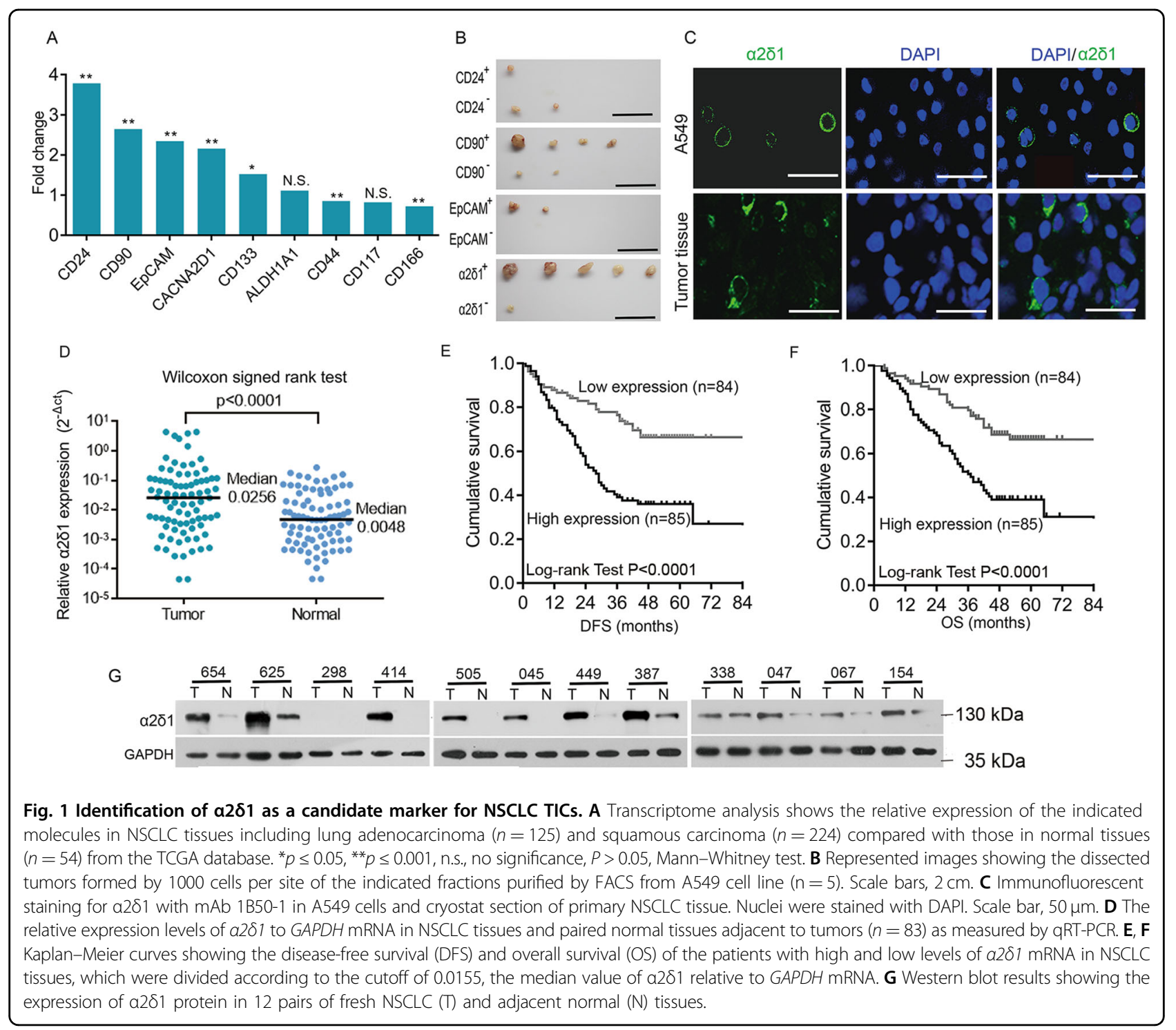

higher rates than their negative counterparts (Fig. 2A, B). Moreover, single cells dissociated from these spheroids could be clonally expanded and subsequently passaged with increased sphere-forming efficiencies, indicating that the $\alpha 2 \delta 1^{+}$cells in these NSCLC cell lines own the in vitro self-renewal capacity.

Next, we serially transplanted purified $\alpha 2 \delta 1^{+}$and $\alpha 2 \delta 1^{-}$ cells from these cell lines into NOD/SCID mice s.c. with limiting dilution to test their tumor-initiation ability. Sorted $\alpha 2 \delta 1^{+}$subsets from A549, H520 and H292 cell lines were sufficient to initiate tumor formation in almost all the transplanted mice, whereas no significant tumor formation was observed for most of the mice transplanted with $\alpha 2 \delta 1^{-}$ counterparts (Fig. 2C, Table 1). Further sorting and retransplanting of the $\alpha 2 \delta 1^{+}$subsets from the tumors formed by the $\alpha 2 \delta 1^{+}$cells revealed that these cells were again able to generate tumors in the secondary recipient mice
(Table 1). The tumorigenic capabilities of the $\alpha 2 \delta 1^{+}$and $\alpha 2 \delta 1^{-}$cells were further tested using purified fractions from fresh tumor tissues of NSCLC. As few as $100 \alpha 2 \delta 1^{+}$ cells purified from tumor tissues of 4 cases out of 5 patients tested were enough to initiate tumor growth in most of the transplanted mice, whereas only tiny nodules were observed in 2 out of 34 mice transplanted with $\alpha 2 \delta 1^{-}$cells (Table 1). Hematoxylin and eosin staining revealed that the histological features of tumors formed by $\alpha 2 \delta 1^{+}$cells are morphologically heterogeneous, resembling those of the tumors from which they originated (Fig. 2D). These results indicate that $\alpha 2 \delta 1^{+}$NSCLC cells are able to drive the formation of heterogeneity of tumors and own the in vivo self-renewal capability.

We subsequently assessed the differentiation potential of the purified $\alpha 2 \delta 1^{+}$cells both in vitro and in vivo. After sorted $\alpha 2 \delta 1^{+}$cells from A549 and H520 cell lines were 


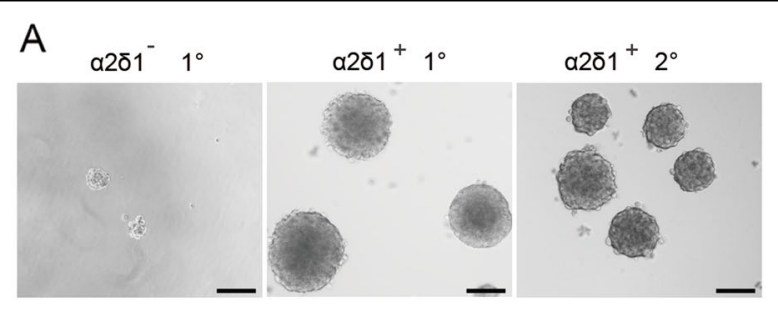

B

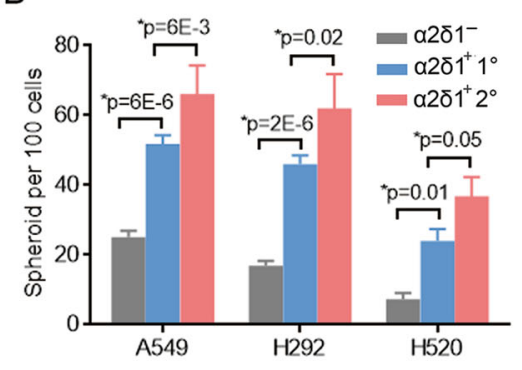

D

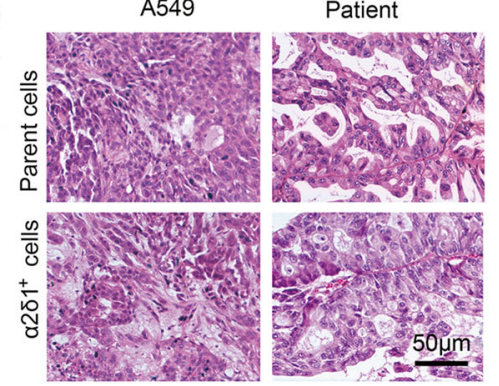

E
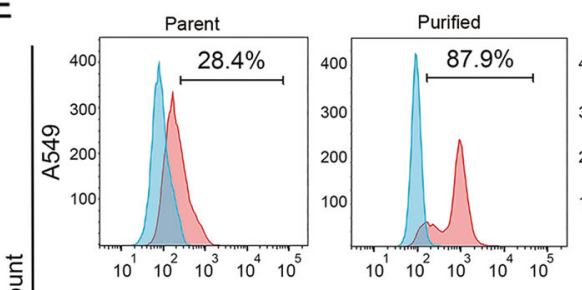

¿े

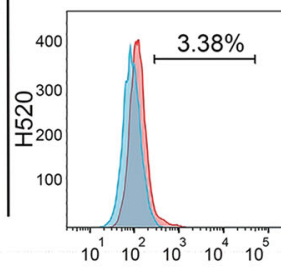

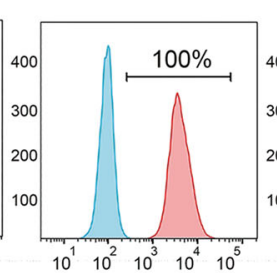

Fluorescence intensity
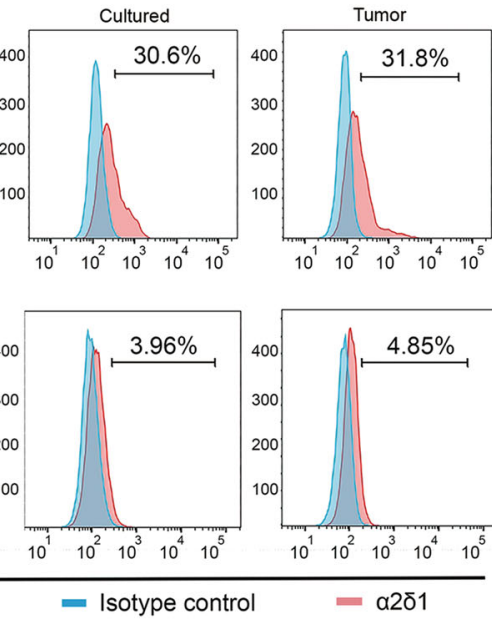

C

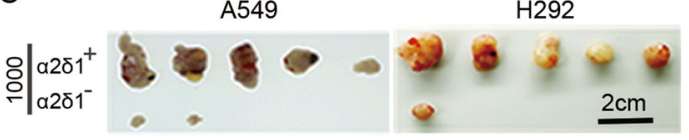

$\mathrm{F}$

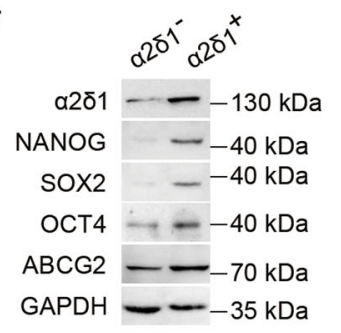

G

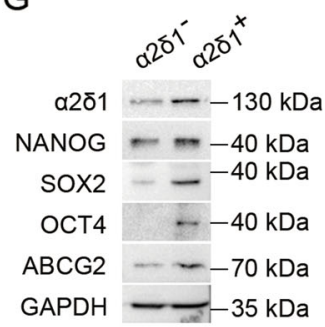

$\mathrm{H}$
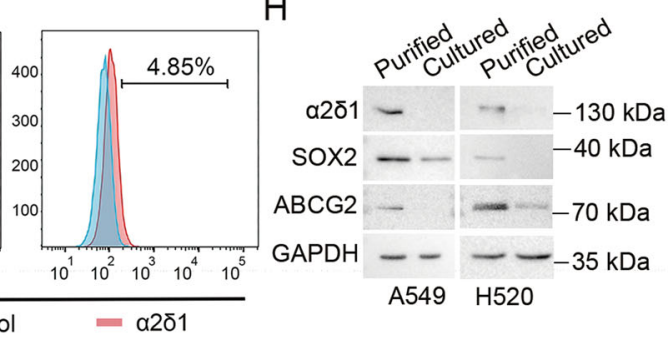

Fig. 2 The stem cell-like properties of $\mathbf{a} 2 \delta \mathbf{1}^{+}$NSCLC cells. A Representative phase-contrast photographs showing the primary $\left(1^{\circ}\right)$ and serially passaged $\left(2^{\circ}\right)$ spheroids formed by indicated subpopulations sorted from $\mathrm{H} 520$ cell line by FACS. Scale bars, $100 \mu \mathrm{m}$. B Histograms show the primary $\left(1^{\circ}\right)$ and serially passaged $\left(2^{\circ}\right)$ spheroid formation efficiencies of the $a 2 \delta 1^{+}$cells as compared with a $2 \delta 1^{-}$cells sorted from indicated sources. Data are presented as the mean \pm SD of three independent experiments $(n=3)$. *Student's $t$-test. C Photographs of dissected tumors formed by sorted a $2 \delta 1^{+}$ and $\mathrm{a} 281^{-}$cells from indicated sources $(n=5)$. $\mathbf{D}$ The histology of the tumors formed by a $2 \delta 1^{+}$cells sorted from the A549 cell line and the primary tumor of one NSCLC patient was compared with that of the parent A549 tumor and the original patient tumor, respectively, by H.E. staining. E Flow cytometry analysis of the percentage of $a 2 \delta 1^{+}$fractions in parental cells (Parent), freshly FACS-purified a $2 \delta 1^{+}$subpopulations (Purified) and purified $\mathrm{a}_{2} \delta 1^{+}$cells cultured in 10\% FBS for 2 weeks (Cultured) or engrafted into NOD/SCID mice (Tumor). $\mathbf{F}-\mathbf{H}$ The expression of the indicated molecules in purified $\mathrm{a}_{2} \delta 1^{+}$and $\mathrm{a} 2 \delta 1^{-}$cells from A549 (F), H520 (G) cells lines, as well as in sorted a $2 \delta 1^{+}$A549 and H520 fractions cultured in FBS-containing medium for two weeks $(\mathbf{H})$ was analyzed by Western blotting. GAPDH serves as loading control.

cultivated in a medium containing $10 \%$ FBS for two weeks, the percentages of $\alpha 2 \delta 1^{+}$fractions reduced from more than $87 \%$ to those similar to the parent cell lines (Fig. 2E). Furthermore, the $\alpha 2 \delta 1^{+}$percentage in the tumors formed by $\alpha 2 \delta 1^{+}$subsets also decreased to $31.8 \%$ and $4.85 \%$ for A549 and H520, respectively (Fig. 2E). The data demonstrate that $\alpha 2 \delta 1^{+}$NSCLC cells are able to differentiate into $\alpha 2 \delta 1^{-}$cells.
Finally, the expression of stem cell-related factors such as NANOG, OCT4, SOX2 and ABCG2 was dramatically higher in the sorted $\alpha 2 \delta 1^{+}$fractions of A549 and H520 cell lines than their negative counterparts. As additional evidence to support that $\alpha 2 \delta 1^{+}$NSCLC cells have the capacity of differentiation, the expression of stem cellrelated molecules including $\alpha 2 \delta 1$, SOX2, and ABCG2 was also downregulated in purified $\alpha 2 \delta 1^{+}$A549 and H520 
Table 1 The tumorigenicity of $a 2 \delta 1^{+}$and $a 2 \delta 1^{-}$cells of NSCLC in NOD/SCID mice.

\begin{tabular}{|c|c|c|c|c|c|}
\hline \multirow[t]{2}{*}{ Tumor cells } & \multirow[t]{2}{*}{$\alpha 2 \delta 1$} & \multicolumn{2}{|c|}{$\begin{array}{l}\text { Tumor } \\
\text { formation }\end{array}$} & \multirow{2}{*}{$\begin{array}{l}\text { Frequency of } \\
\text { tumorigenic cells } \\
(95 \% \mathrm{Cl})\end{array}$} & \multirow[t]{2}{*}{$P$ value } \\
\hline & & 1000 & 100 & & \\
\hline \multirow[t]{3}{*}{ A549 } & Negative & $2 / 5$ & $0 / 5$ & $\begin{array}{l}1 / 2213(1 / 8821-1 / \\
555)\end{array}$ & $2.60 \mathrm{E}-05^{\mathrm{c}}$ \\
\hline & Positive & $5 / 5$ & $4 / 5$ & $1 / 62(1 / 185-1 / 21)$ & \\
\hline & ST & $5 / 5$ & $4 / 5$ & $1 / 62(1 / 185-1 / 21)$ & \\
\hline \multirow[t]{3}{*}{$\mathrm{H} 292$} & Negative & $1 / 5$ & $0 / 5$ & $\begin{array}{l}\text { 1/4983 (1/35191-1/ } \\
706)\end{array}$ & $2.28 \mathrm{E}-06^{\mathrm{c}}$ \\
\hline & Positive & $5 / 5$ & $4 / 5$ & $1 / 62.1(1 / 185-1 / 21)$ & \\
\hline & ST & $5 / 5$ & $4 / 5$ & $1 / 62.1(1 / 185-1 / 21)$ & \\
\hline \multirow[t]{3}{*}{$\mathrm{H} 520$} & Negative & $1 / 5$ & $0 / 5$ & $\begin{array}{l}\text { 1/4983 (1/35191-1/ } \\
706)\end{array}$ & $0.0383^{c}$ \\
\hline & Positive & $3 / 5$ & $2 / 5$ & $\begin{array}{l}1 / 711(1 / 1928-1 / \\
263)\end{array}$ & \\
\hline & ST & $5 / 5$ & $3 / 5$ & $1 / 109(1 / 348-1 / 34)$ & \\
\hline \multirow[t]{2}{*}{$7494^{\mathrm{a}}$} & Negative & $0 / 3$ & $0 / 3$ & N.A. & \\
\hline & Positive & $3 / 3$ & $3 / 3$ & N.A. & \\
\hline \multirow[t]{2}{*}{$9157^{a}$} & Negative & $0 / 3$ & $0 / 3$ & N.A. & \\
\hline & Positive & $0 / 3$ & $0 / 3$ & N.A. & \\
\hline \multirow[t]{2}{*}{$0296^{a}$} & Negative & $0 / 1$ & $0 / 1$ & N.A. & \\
\hline & Positive & $1 / 1$ & $0 / 1$ & N.A. & \\
\hline \multirow[t]{2}{*}{$7470^{b}$} & Negative & $1 / 5$ & $0 / 5$ & $\begin{array}{l}\text { 1/4983 (1/35191-1/ } \\
706)\end{array}$ & $0.09^{c}$ \\
\hline & Positive & $3 / 5$ & $1 / 5$ & $\begin{array}{l}1 / 921(1 / 2617-1 / \\
324)\end{array}$ & \\
\hline \multirow[t]{2}{*}{$9613^{b}$} & Negative & $1 / 5$ & $0 / 5$ & $\begin{array}{l}\text { 1/4983 (1/35191-1/ } \\
706)\end{array}$ & $0.038^{c}$ \\
\hline & Positive & $3 / 5$ & $2 / 5$ & $\begin{array}{l}1 / 711(1 / 1928-1 / \\
263)\end{array}$ & \\
\hline
\end{tabular}

$N . A$. not applied, The calculation of TIC frequencies is not applicable because there are too few animals transplanted, ST serial transplantation.

aprimary NSCLC tissue.

${ }^{\mathrm{b}}$ NSCLC PDX tissues.

'Compared between the $\mathrm{a}_{2} \delta 1^{+}$and $\mathrm{a}_{2} \delta 1^{-}$subpopulations.

fractions after cultivation in FBS-containing medium for 2 weeks (Fig. $2 \mathrm{H}$ ).

Collectively, the above data demonstrate that $\alpha 2 \delta 1$ defines a subset of NSCLC TICs with stem cell-like properties.

\section{The $a 2 \delta 1^{+}$NSCLC cells are resistant to conventional chemotherapy}

To address whether $\alpha 2 \delta 1^{+}$TICs of NSCLC are resistant to conventional chemotherapy, we first detected the ratio change of $\alpha 2 \delta 1^{+}$TICs in the cell lines A549 and H520 after treatment with carboplatin and paclitaxel. The $\alpha 2 \delta 1^{+}$TICs were significantly enriched after carboplatin and paclitaxel treatment in the two cell lines (Fig. 3A, B). Moreover, the apoptotic rates of $\alpha 2 \delta 1^{+}$TICs were remarkably lower than their negative counterparts with the treatment of carboplatin (Fig. 3C, D). These data indicate that $\alpha 2 \delta 1^{+}$TICs are indeed resistant to conventional chemotherapy drugs.

\section{TICs are more enriched in $a 2 \delta 1^{+}$cells than in $\mathrm{CD}_{166^{+}}$, or $\mathrm{CD}_{133^{+}}$ones}

We then sought to determine the correlation between $\alpha 2 \delta 1$ and CD133, or CD166, the two widely used NSCLC TIC markers, by dual-color flow cytometry. Although the majority of $\alpha 2 \delta 1^{+}$cells were positive for CD133 in the NSCLC cell lines H520 and PC9, very few $\alpha 2 \delta 1^{+}$cells were positive for CD133 in the A549 cell line. Conversely, $<40 \%$ of $\mathrm{CD} 133^{+}$cells were positive for $\alpha 2 \delta 1$ in all the cell lines tested (Fig. 3E). The data indicate that there is no definite correlation existed between $\alpha 2 \delta 1$ and CD133 in NSCLC cell lines. However, more than $84 \%$ of $\alpha 2 \delta 1^{+}$cells were clearly CD166 positive but not vice versa in these cell lines (Fig. 3E), suggesting that $\alpha 2 \delta 1^{+}$cells are a subset of CD166 ${ }^{+}$NSCLC cells.

To further address which marker is the best to identify NSCLC TICs, we performed a side-by-side comparison of the tumorigenic potential among $\alpha 2 \delta 1^{+}, \mathrm{CD} 133^{+}$, and $\mathrm{CD}_{166}{ }^{+} \mathrm{A} 549$ cells in NOD-SCID mice. In consistent with the results reported in literature ${ }^{10}$, we did find the tumorigenic potential of $\mathrm{CD} 166^{+}$cells was slightly stronger than that of $\mathrm{CD}_{133^{+}}$ones. However, the tumorinitiation ability of $\alpha 2 \delta 1^{+}$cells is the highest among these population (Fig. 3F, Supplementary Table 5), indicating that $\alpha 2 \delta 1$ is the most robust marker for enriching NSCLC TICs compared with CD133 and CD166.

\section{The function of $a 2 \delta 1$ in the acquisition and maintenance of TIC properties}

To test if $\alpha 2 \delta 1$ play any roles in the acquisition and subsequent maintenance of the properties of NSCLC TICs, we performed both loss-of-function and gain-offunction studies in NSCLC cell lines. We first infected FACS-purified $\alpha 2 \delta 1^{+}$subsets of A549 and H520 cell lines with lentiviruses harboring shRNAs against $\alpha 2 \delta 1$ to address whether $\alpha 2 \delta 1$ is required for the maintenance of TIC properties. Compared with the cells infected with lentivirus harboring scramble shRNA, $\alpha 2 \delta 1$ knockdown resulted in downregulation of stem cell-related genes such as NANOG, SOX2, and ABCG2 (Fig. 4A, B), as well as remarkable inhibition of both the spheroid formation efficiencies and the tumorigenic potential of these $\alpha 2 \delta 1^{+}$ cells (Fig. 4C-E, Table 2).

We next overexpressed $\alpha 2 \delta 1$ in the cell lines A549 and $\mathrm{H} 520$ to test if $\alpha 2 \delta 1$ is adequate to enable $\alpha 2 \delta 1^{-}$cells to 

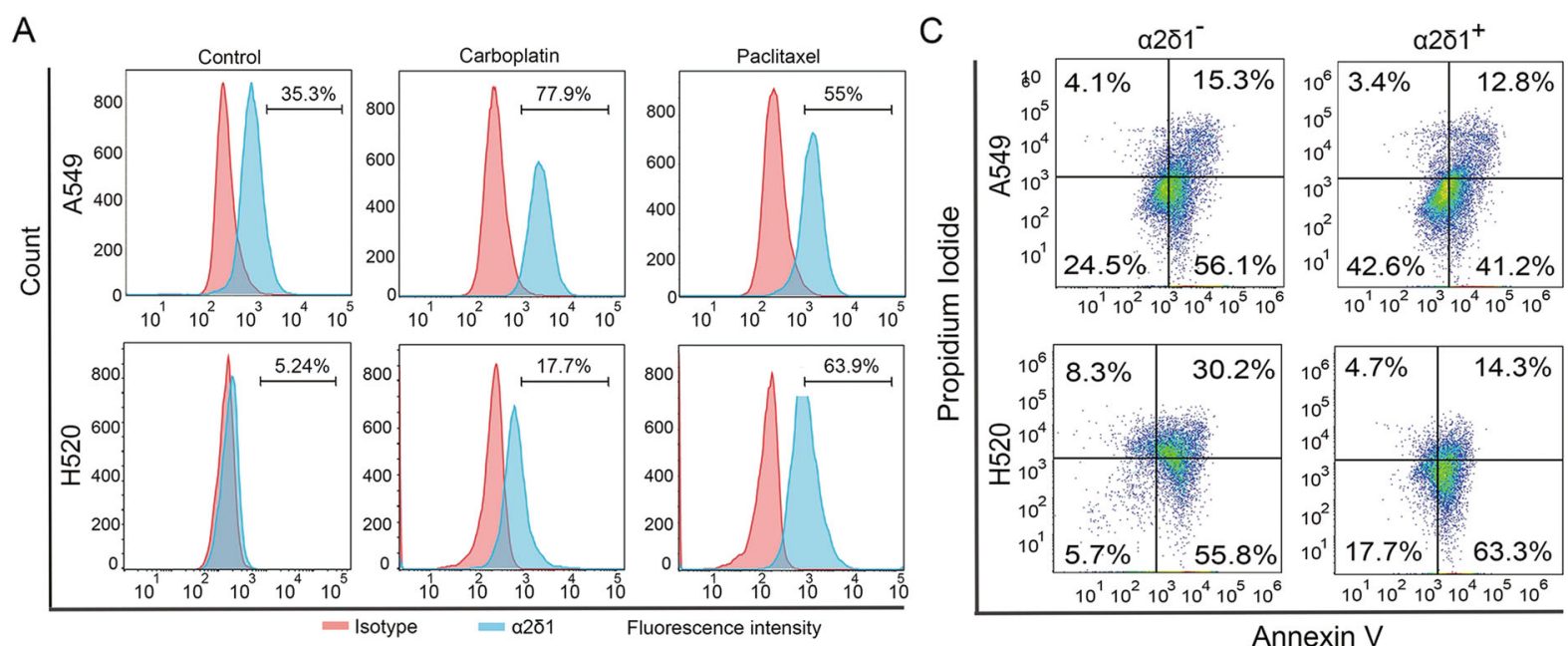

B

Annexin $\mathrm{V}$

D

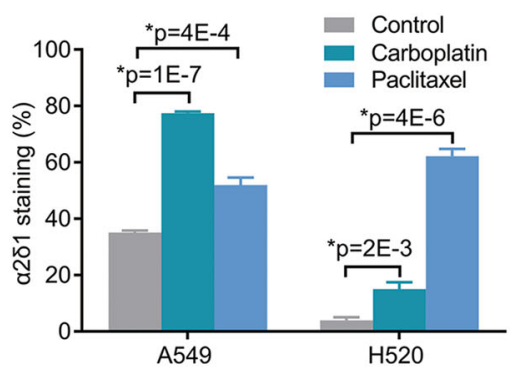

E

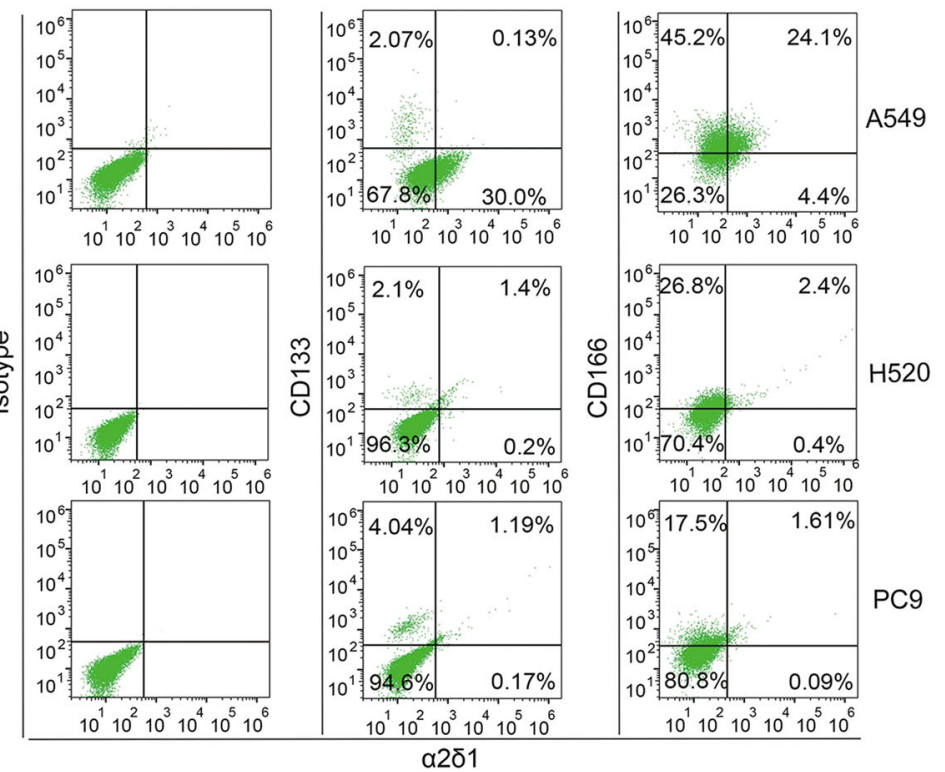

$\mathrm{F}$

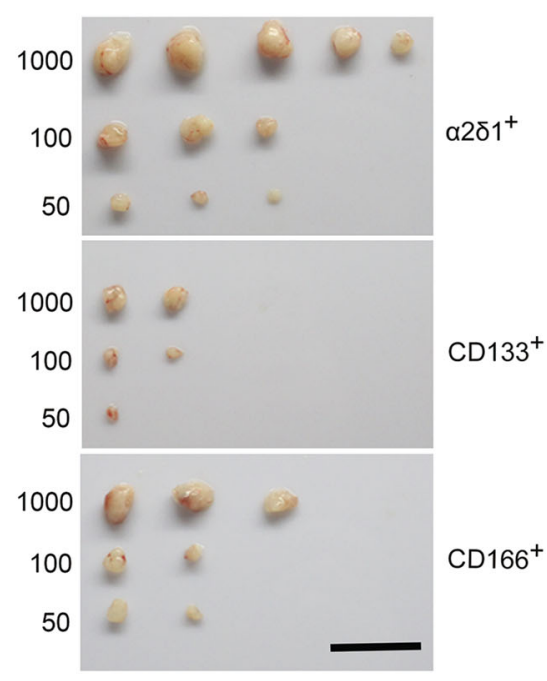

Fig. 3 Characterization of $\mathbf{a} 2 \delta \mathbf{1}^{+}$TICs of NSCLC. A Representative flow cytometry analysis of $a 2 \delta 1^{+}$fractions following carboplatin ( $\left.10 \mu m o l / L\right)$ and paclitaxel $(1 \mathrm{nmol} / \mathrm{L})$ treatment for $96 \mathrm{~h}$. B Histograms showing the change of the percentage of $\mathrm{a} 2 \delta 1^{+}$cells after carboplatin and paclitaxel treatment. C Representative flow cytometry analysis of the apoptosis of both the $a_{2} \delta 1^{+}$and $a_{2} \delta 1^{-}$cells from indicated sources after carboplatin treatment for $48 \mathrm{~h}$ at $10 \mu \mathrm{mol} / \mathrm{L}$ as measured by flow cytometry. D Histograms showing the percentage of apoptotic cells of indicated subsets upon carboplatin treatment. E The relationship of the expression of a2 $\delta 1$ with CD133 and CD166 as detected by flow cytometry in the indicated NSCLC cell lines. $\mathbf{F}$ Side-by-side comparison of the tumorigenic potential of $a 281^{+}$cells with that of $\mathrm{CD}_{133^{+}}$and $\mathrm{CD}_{166^{+}}$A549 cells by limited dilution transplantation into NOD/SCID mice ( $n=5$ for each group). Scale bar, $2 \mathrm{~cm}$. The error bars in (B) and (D) represent SD of three independent experiments. *Student's t-test. 


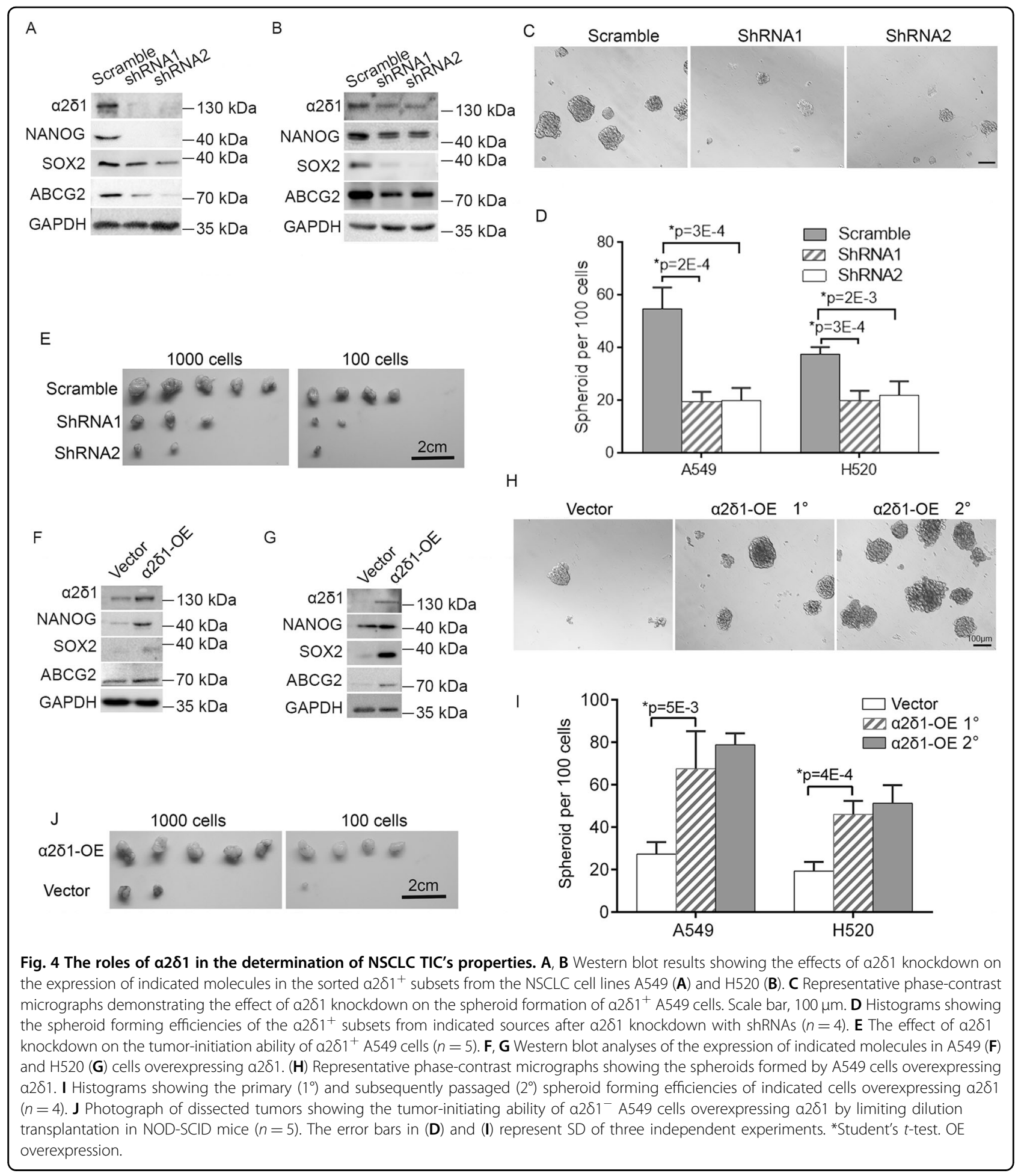

acquire stem cell-like phenotypes. Ectopic expression of $\alpha 2 \delta 1$ in these $\alpha 2 \delta 1^{-}$cells led to upregulation of a series of stem cell-related genes tested including NANOG, SOX2, and ABCG2 (Fig. 4, F, G), as well as significantly enhanced ability to initiate spheroid formation and to expand in subsequent serial propagation when grown in serum-free medium (Fig. 4, H, I), and increased tumorigenic capacity in NOD/SCID mice (Fig. 4J, Table 2).

These data demonstrate that $\alpha 2 \delta 1$ is sufficient to reprogram $\alpha 2 \delta 1^{-}$cells into TICs and is essential for the maintenance of the TIC properties of $\alpha 2 \delta 1^{+}$ NSCLC cells. 
Table 2 The tumorigenicity of indicated cells with a2 21 knockdown or overexpression.

\begin{tabular}{ccccc}
\hline Group & $\begin{array}{l}\text { Tumor } \\
\text { fromation }\end{array}$ & $\begin{array}{l}\text { Frequency of } \\
\text { Tumorigenic cells (95\% Cl) }\end{array}$ & $P$ value \\
\cline { 2 - 3 } & $\mathbf{1 0 0 0}$ & $\mathbf{1 0 0}$ & & \\
\hline a281+ $A 549$ Scramble & $5 / 5$ & $4 / 5$ & $1 / 62(1 / 185-1 / 21)$ & \\
a281 shRNA1 & $3 / 5$ & $2 / 5$ & $1 / 712(1 / 1928-1 / 263)$ & 0.002 \\
a281 shRNA2 & $2 / 5$ & $1 / 5$ & $1 / 1445(1 / 4728-1 / 442)$ & $9.63 E-05$ \\
a281+ H520 Scramble & $5 / 5$ & $2 / 5$ & $1 / 184(1 / 609-1 / 56)$ & \\
a281 shRNA1 & $2 / 5$ & $0 / 5$ & $1 / 2212(1 / 8821-1 / 555)$ & 0.0031 \\
a281 shRNA2 & $3 / 5$ & $0 / 5$ & $1 / 1268(1 / 3956-1 / 407)$ & 0.0159 \\
a281- A549 Vector & $2 / 5$ & $1 / 5$ & $1 / 1445(1 / 4728-1 / 442)$ & \\
a281-OE & $5 / 5$ & $4 / 5$ & $1 / 62(1 / 185-1 / 21)$ & $9.63 E-05$ \\
a281- H520 Vector & $2 / 5$ & $0 / 5$ & $1 / 2212(1 / 8821-1 / 555)$ & \\
a281-OE & $4 / 5$ & $2 / 5$ & $1 / 452(1 / 1205-1 / 170)$ & 0.0428 \\
\hline
\end{tabular}

$O E$, overexpression.

\section{The role of a $2 \delta 1$ in driving TIC capacities is Notch- dependent}

To test if Notch signaling pathway associate with the $\alpha 2 \delta 1^{+}$TICs of NSCLC, we first determined the correlation between the expression of $\alpha 2 \delta 1$ and those genes involved in Notch signaling in NSCLC tissues from TCGA database. The expression of $\alpha 2 \delta 1$ was found positively correlated with $\mathrm{NOTCH} 1$ and $\mathrm{NOTCH} 3$, but not NOTCH2 and NOTCH4, of the four Notch universal receptors, and their ligands JAG1, JAG2, DLL1, DLL3 (Fig. $5 \mathrm{~A})$. The positive correlation between the expression of $\alpha 2 \delta 1$ and NOTCH1/NOTCH3 was further validated in 155 cases of NSCLC specimens by qRT-PCR (Fig. 5B). We then checked the expression of NOTCH1 and NOTCH3 in the sorted $\alpha 2 \delta 1^{+}$and $\alpha 2 \delta 1^{-}$fractions from A549 and H520 cell lines. Compared with that in $\alpha 2 \delta 1^{-}$subsets, the expression of $\mathrm{NOTCH} 1$ and $\mathrm{NOTCH} 3$ receptor was much higher in $\alpha 2 \delta 1^{+}$populations purified from both cell lines as demonstrated by Western blotting (Fig. 5C). Forced expression of $\alpha 2 \delta 1$ in $\mathrm{H} 520$ and PC9 cell lines resulted in elevated expression of $\mathrm{NOTCH} 3$, and minor increase of NOTCH1 at protein level. Conversely, knockdown of $\alpha 2 \delta 1$ in purified $\alpha 2 \delta 1^{+}$cells from A549 cell line led to downregulation of both NOTCH1 and NOTCH3 (Fig. 5C). These data indicate that $\alpha 2 \delta 1$ can regulate the expression of $\mathrm{NOTCH} 3$ at least.

We subsequently treated sorted $\alpha 2 \delta 1^{+}$TICs and the $\alpha 2 \delta 1$-overexpressing cells with a $\gamma$-secretase inhibitor, DAPT, to address if $\mathrm{NOTCH}$ was functionally required for the in vitro self-renewal capacity of TICs mediated by $\alpha 2 \delta 1$ using spheroid formation assay. Treatment of $\alpha 2 \delta 1^{+}$ TICs purified from A549 and H520 cell lines resulted in significant suppression of their spheroid formation ability (Fig. 5D, E). Furthermore, when the H520 and PC9 cells with forced expression of $\alpha 2 \delta 1$ were treated with DAPT, the spheroid formation ability mediated by $\alpha 2 \delta 1$ was dramatically attenuated (Fig. 5F, G).

Taken together, these data demonstrate that Notch signaling is essential for the role of $\alpha 2 \delta 1$ in the acquisition and subsequent maintenance of the self-renewal property of NSCLC TICs.

\section{a281 upregulates NOTCH3 through $\mathrm{Ca}^{2+}$-Calcineurin/ NFATc2 signaling pathway}

Since $\alpha 2 \delta 1$ has been reported previously to cause calcium influx into cells by serving as a subunit of voltagedependent calcium channel ${ }^{13,28,29}$, we measured the intracellular $\mathrm{Ca}^{2+}$ levels $\left(\left[\mathrm{Ca}^{2+}\right]_{\mathrm{i}}\right)$ in NSCLC cell lines by flow cytometry to gain insight into the mechanism(s) by which $\alpha 2 \delta 1$ upregulates NOTCH3 and subsequently promotes the properties of $\alpha 2 \delta 1^{+}$TICs. Significantly higher levels of $\left[\mathrm{Ca}^{2+}\right]_{\mathrm{i}}$ were detected in the $\alpha 2 \delta 1^{+}$cells purified from A549, H520, and PC9 cell lines than in their negative counterparts (Fig. 6A). Knockdown of $\alpha 2 \delta 1$ in purified $\alpha 2 \delta 1^{+}$A549 and H520 cells with shRNAs resulted in remarkable decrease of $\left[\mathrm{Ca}^{2+}\right]_{i}$, while forced expression of $\alpha 2 \delta 1$ in $\mathrm{H} 520$ and PC9 cells led to significantly opposite effect (Fig. 6B, C). As additional evidence to support that $\alpha 2 \delta 1$ was functionally involved in the influx of $\mathrm{Ca}^{2+}$ into the cells of $\alpha 2 \delta 1^{+}$NSCLC TICs, the levels of $\left[\mathrm{Ca}^{2+}\right]_{\mathrm{i}}$ could be inhibited significantly in sorted $\alpha 2 \delta 1^{+}$A549 and H520 cells, as well as A549 and H520 cells overexpressing $\alpha 2 \delta 1$ when these cells were treated with pregabalin, a wellcharacterized inhibitor of $\alpha 2 \delta 1$ (Fig. 6D, E).

We then tested if elevated $\left[\mathrm{Ca}^{2+}\right]_{i}$ could activate the NFAT signaling pathway in $\alpha 2 \delta 1^{+}$NSCLC TICs. Of the 4 NFATc isoforms, the isoform NFATc2 was found expressed at a much higher level in purified $\alpha 2 \delta 1^{+}$fractions from both the A549 and H520 cell lines than their $\alpha 2 \delta 1^{-}$populations as demonstrated by qRT-PCR (Fig. 6F). Furthermore, the expression of NFATc2 mRNA was positively correlated with $\alpha 2 \delta 1 \mathrm{mRNA}$ in clinical NSCLC specimens (Fig. 6G). Subsequently treatment of $\alpha 2 \delta 1^{+}$ A549 cells with cyclosporin A(CsA), a calcineurin inhibitor, could dramatically downregulate the expression of stem cell-related genes such as NOTCH3 and ABCG2 (Fig. 6H). Importantly, cyclosporin A could also significantly suppress the spheroid forming frequencies of the $\alpha 2 \delta 1^{+}$subpopulation of A549 and H520 cells (Fig. 6I, J).

All of these data suggest that the roles of $\alpha 2 \delta 1$ in the upregulation of the stem cell-related genes including $\mathrm{NOTCH} 3$ and subsequent driving the self-renewal properties of NSCLC TICs are dependent on $\mathrm{Ca}^{2+}$-calcineurin-NFATc2 signaling.

\section{NFATC2 directly activates the expression of ABCG2 and NOTCH3}

To further test if NFATc2 transcriptionally upregulates the expression of stem cell-related genes of $\alpha 2 \delta 1^{+}$ 


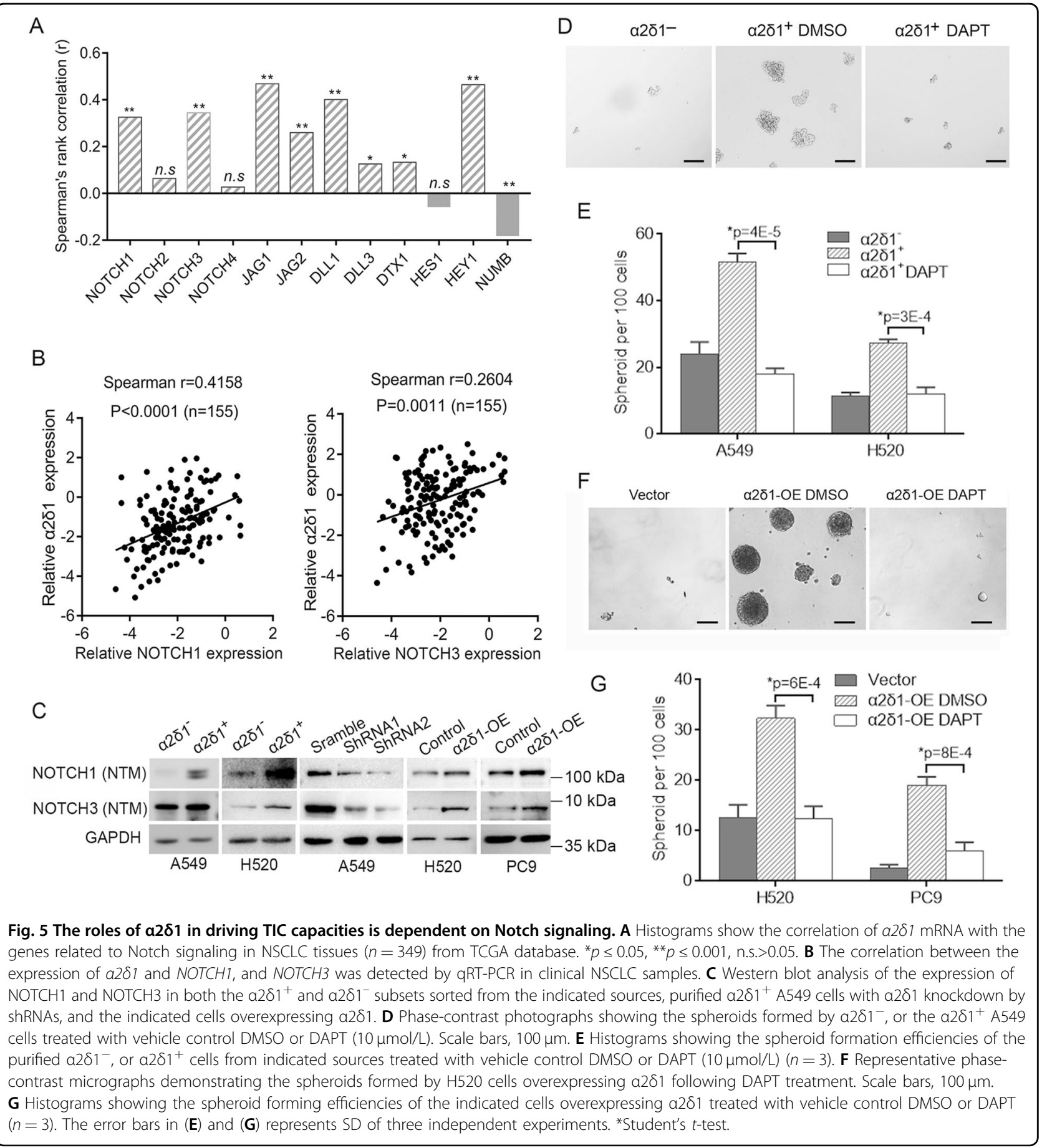

TICs, we performed NFATc2 binding site analysis in the promoters of ABCG2 and NOTCH3 using JASPAR online software. There were a total of 2 and 5 presumptive NFATc2 binding sites found within the region from -1000 to $1 \mathrm{bp}$ bases in the promoters of NOTCH3 and ABCG2, respectively (Fig. 7A). The occupancies of NFATc2 at the promoters of ABCG2 and NOTCH3 were then validated by PCR following ChIP assay (Fig. 7B). Significant binding of NFATc2 to the promoters of ABCG2 and NOTCH3 was revealed with more than a five-fold increase of precipitated target DNA (Fig. 7C, D).

To determine whether these NFATc2 sites were involved in the activation of the promoters of ABCG2 and 


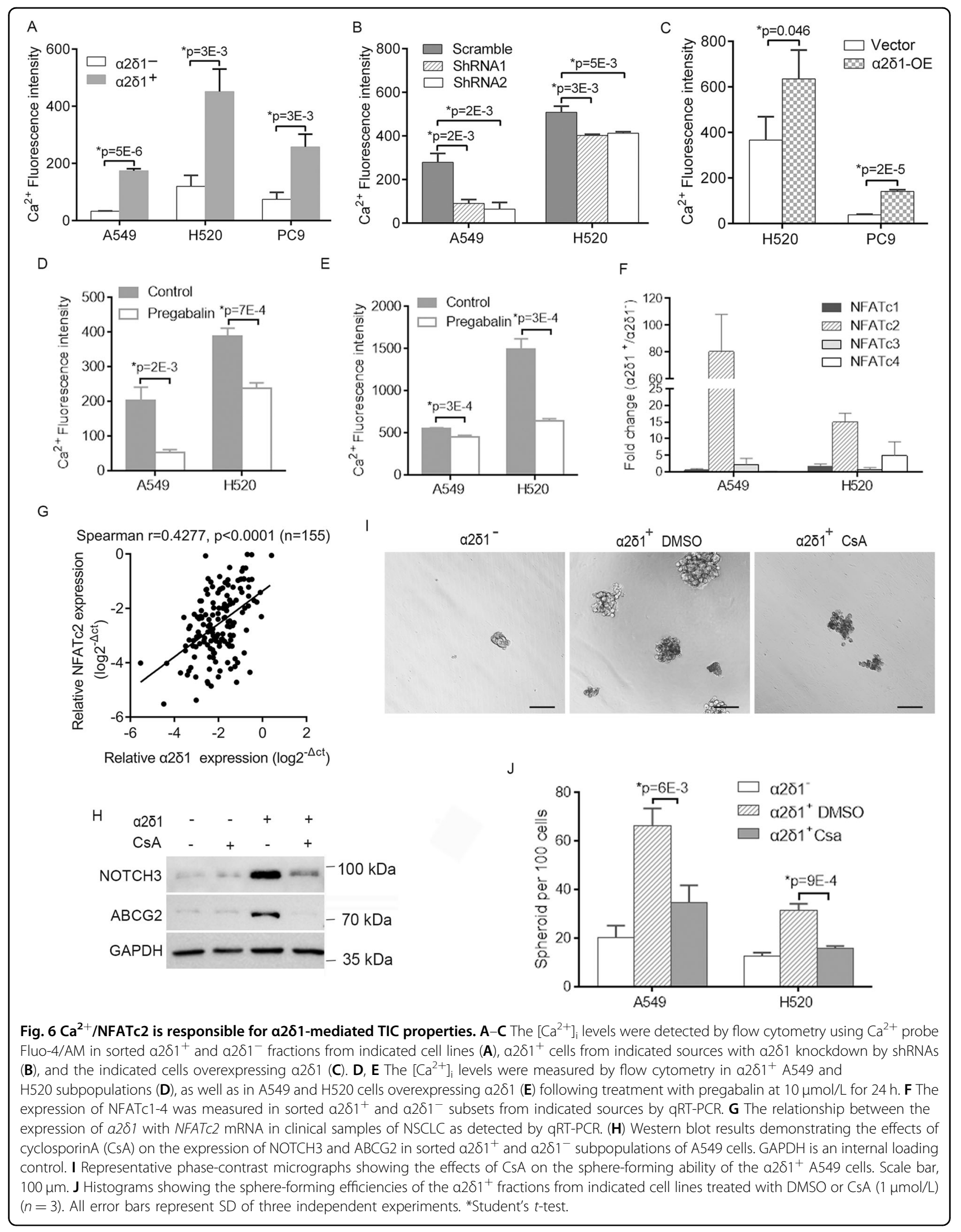



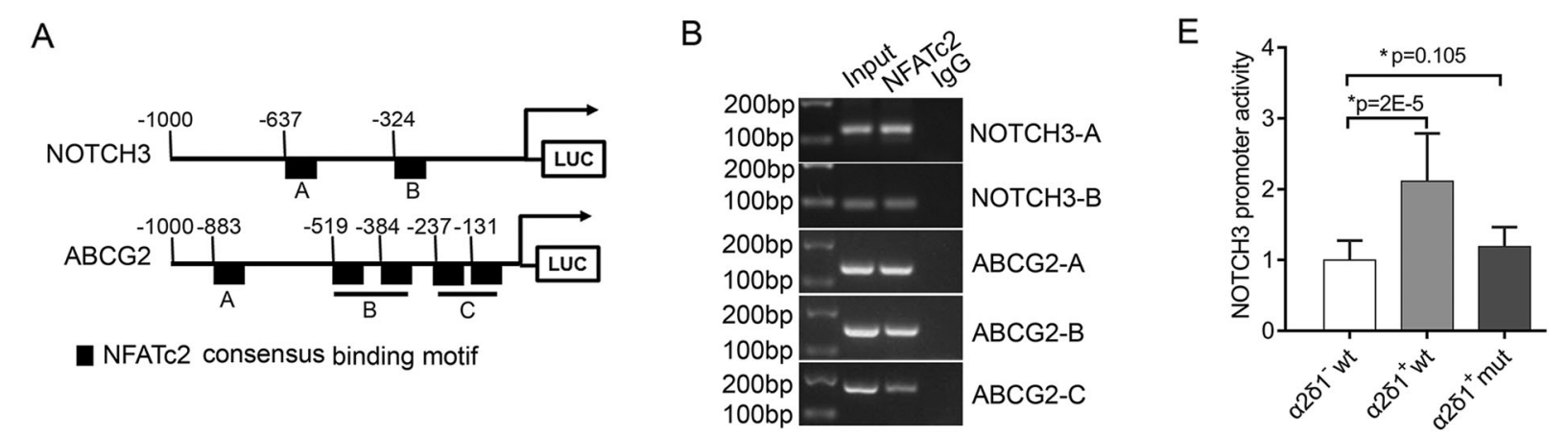

C

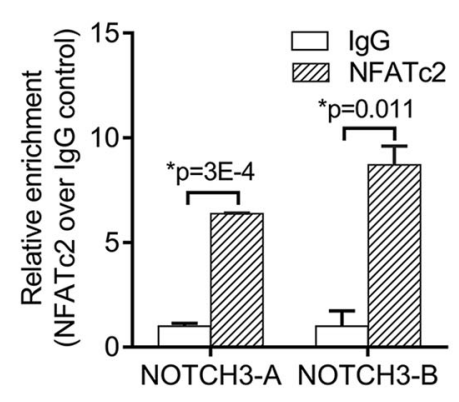

G

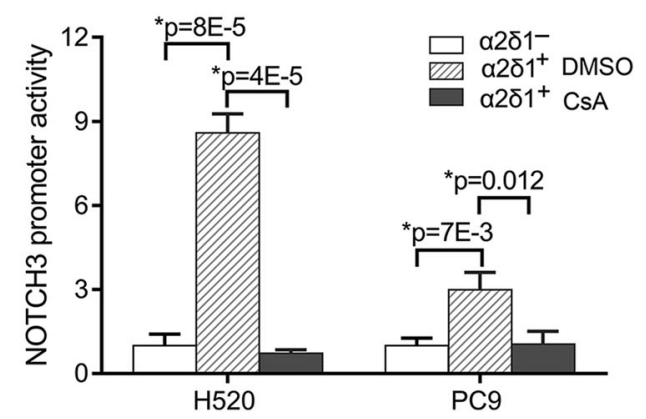

D

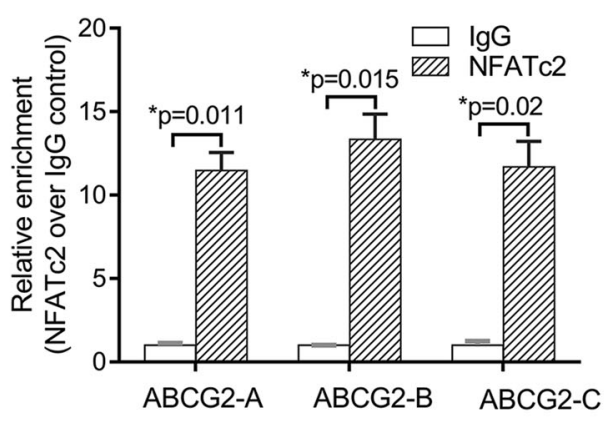

$\mathrm{H}$

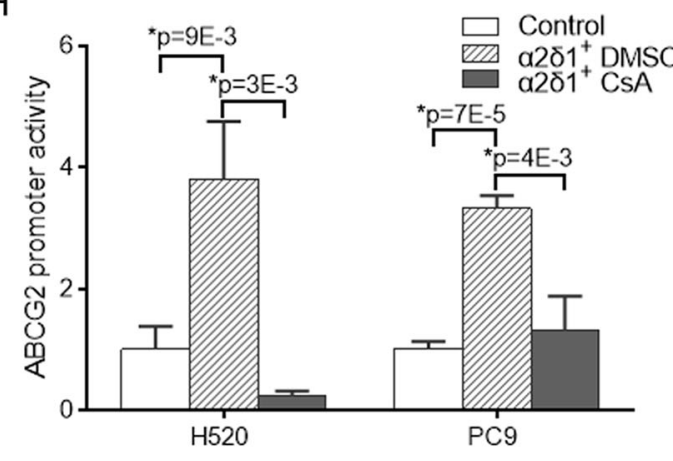

Fig. 7 NFATC2 activates the expression of NOTCH3 and ABCG2 by binding to their promoters. A Schematic depiction of the NOTCH3 and ABCG2 promoters that are fused to a luciferase reporter gene. B ChIP assay was performed using control IgG and anti-NFATc2 antibody in A549 cells. The precipitated DNA was amplified with primer pairs flanking the putative NFATc2-binding regions of indicated promoters as depicted in (A) by PCR. C, D Quantitative analysis of NFATC2-binding to the indicated promoter regions of NOTCH3 and ABCG2 was determined by ChIP assay followed by qPCR. E, $\mathbf{F}$ The luciferase activities of NOTCH3 and ABCG2 reporters in the indicated cell fractions. The indicated reporters with wild type or mutant NFATc2-binding consensus sequences were co-transfected with PRL-TK plasmid, which serves as an internal control, into sorted a2 $\delta 1^{-}$and $a 2 \delta 1^{+}$ A549 cells. Luciferase values were normalized to Renilla reporter activities. G, H The luciferase activities of wild type NOTCH3 and ABCG2 reporters in the indicated cell fractions treated with control vehicle DMSO or CSA $(1 \mu \mathrm{mol} / \mathrm{L})$. All data are presented as mean \pm SD of three independent experiments $(n=3)$. *Student's $t$-test.

$\mathrm{NOTCH} 3$, we generated the luciferase reporter constructs driven by ABCG2 or NOTCH3 promoters containing either the wild type or the mutant NFATc2 binding sites. Their activities were tested in purified $\alpha 2 \delta 1^{+}$and $\alpha 2 \delta 1^{-}$ subsets of A549 cells. The reporter activities of both the wild type NOTCH3 and ABCG2 promoters were dramatically higher in the $\alpha 2 \delta 1^{+}$subpopulation than those in the respective $\alpha 2 \delta 1^{-}$subset, and their activities in $\alpha 2 \delta 1^{+}$ cells could be inhibited by CsA treatment, whereas the activities of those reporters containing mutant NFAT2c binding sites showed no significant difference in both the $\alpha 2 \delta 1^{+}$and $\alpha 2 \delta 1^{-}$subpopulation (Fig. 7E-H).

These data collectively confirmed that the direct binding of NFATc2 to the promoters of ABCG2 and $\mathrm{NOTCH} 3$ is responsible for the activation of the expression of these two genes in $\alpha 2 \delta 1^{+}$TICs of NSCLC. 

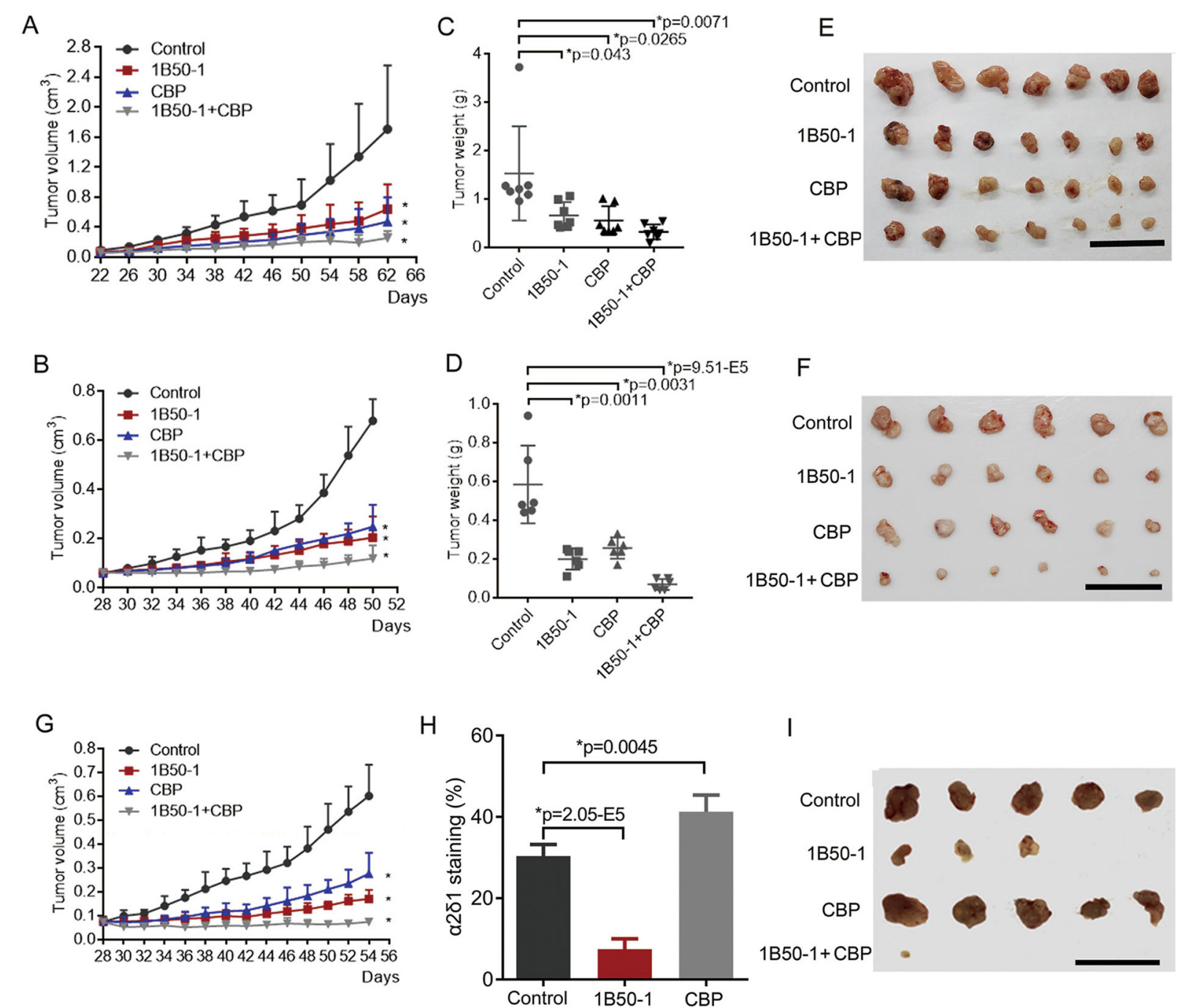

I

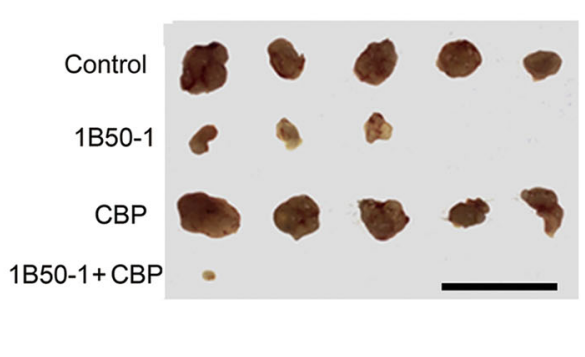

Fig. 8 The therapeutic effects of anti-a2 $\delta 1$ mAb1B50-1 on established NSCLC engraftments in NOD/SCID mice. A, B Growth curves of A549 (A) and H520 (B) engraftments treated with $800 \mu \mathrm{g} /$ mouse 1B50-1, $1.5 \mathrm{mg} / \mathrm{kg}$ carboplatin (CBP), or the combination of both, every other day after the tumors were visible. C, D The histograms showing the average weight of the dissected tumors of A549 (C) and H520 (D) engraftments treated with indicated regimens. E, F Photographs of the dissected tumors of A549 (E) and H520 (F) engraftments received the indicated treatments. (G) Growth curves of one NSCLC PDX tumors i.p. injected with 1B50-1, CBP, or the combination of both. $\mathbf{H}$ Histogram demonstrates the percentage of a2 $\delta 1^{+}$ cells in the residual tumors of A549 xenografts received the indicated treatment as detected by flow cytometry. I Dissected tumors showing the tumor-initiating ability of the A549 engraftment residues after each drug treatment, which was assayed by re-transplanting $10^{4}$ cells per site with Matrigel into NOD/SCID mice. Scale bars, $5 \mathrm{~cm}$. All error bars indicate SD. ${ }^{*} p \leq 0.05$, compared with vehicle control group. Student's $t$-test.

\section{Anti-a2 $\delta 1$ antibody retards the growth of NSCLC in vivo and eradicates TICs}

The above results prompted us to investigate whether blocking the function of $\alpha 2 \delta 1$ with mAb1B50-1 could have a therapeutic effect on NSCLC by eliminating TICs. The therapeutic effect of 1B50-1 on established engraftments of the cell lines A549 and H520 in NOD/SCID mice were tested by administering mAb1B50-1 i.p. alone, or combined with cytotoxic drug carboplatin. As shown in Fig. 8A-F, the growth of both the A549 and H520 xenografts was significantly suppressed with the treatment of mAb1B50-1, by ratios of as many as $56.9 \%$ and $65.8 \%$, respectively, which were comparable to those with the treatment of carboplatin, whereas the combinational treatment of $\alpha 2 \delta 1 \mathrm{mAb}$ with carboplatin resulted in inhibition rates of $79.0 \%$ and $88.3 \%$ on the A549 and $\mathrm{H} 520$ xenografts, respectively. Similar effects were also observed on a patient-derived xenograft model with these treatments (Fig. 8G).

To address if the treatments have any effects on the content of TICs, the percentages of TICs in the residues of the treated A549 xenografts were then detected by flow 
cytometry. Comparing with the control group treated with control vehicle, the proportion of $\alpha 2 \delta 1^{+}$cells decreased remarkably in the residual tumors treated with anti- $\alpha 2 \delta 1$ antibody alone, whereas the $\alpha 2 \delta 1^{+}$cells were dramatically enriched in those residual tumors treated with carboplatin (Fig. 8H). Subsequent transplantation $10^{4}$ cells from tumors that received 1B50-1 treatment into recipient mice generated very tiny nodules in three out of five mice, while those dissociated cells from control vehicle and carboplatin-treated tumors formed significantly larger tumors in all the transplanted mice. Interestingly, only a negligible nodule was found in one out of five mice transplanted with residual cells from an engrafted tumor received combined therapy (Fig. 8I). These data suggest that TICs were indeed reduced following anti- $\alpha 2 \delta 1$ antibody therapy in vivo, especially after the combinational treatment.

\section{Discussion}

The identification of functional surface markers that could better define TICs with distinct phenotypes is instrumental for developing efficient strategies of targeted therapies in NSCLC patients. In the present study, we demonstrate that a subpopulation of TICs could be specifically isolated from cell lines and fresh tumor tissues of NSCLC using a mAb against $\alpha 2 \delta 1$. These $\alpha 2 \delta 1^{+}$NSCLC cells are more enriched for TICs than those defined by CD133, or CD166, the two well-recognized surface markers of NSCLC TICs ${ }^{8,10,12}$. Interestingly, $\alpha 2 \delta 1$ was found to be functionally sufficient and indispensable for the acquirement and subsequently maintenance of the stem cell-like properties of these TICs via the influx of calcium into cells, which in turn activates the calcium signaling pathway cascade. Hence, $\alpha 2 \delta 1$ marks a unique subpopulation of TICs of NSCLC with highly activated calcium signaling.

Our current study identified that the role of $\alpha 2 \delta 1$ in driving the stem cell-like properties of NSCLC TICs is Notch signaling dependent. Moreover, $\alpha 2 \delta 1$ was demonstrated to be able to activate the expression of stem cell-related genes such as NOTCH3 and ABCG2 through the $\mathrm{Ca}^{2+}$-calcineurin-NFAT pathway. Although the crosstalk between Notch and calcium signaling pathways has been appreciated in a couple of cellular processes ${ }^{30,31}$, to the best of our knowledge, this is the first study linking the role of calcium influx mediated by $\alpha 2 \delta 1$ to Notch signaling activation in the biology of NSCLC TICs, uncovering an unappreciated molecular mechanism on how Notch, a key regulator of many reported TIC population $^{24,32}$, is activated in NSCLC TICs. In addition to its ability to activate the Notch signaling, the $\mathrm{Ca}^{2+}$. calcineurin-NFAT pathway could up-regulate the expression of ABCG2, the molecule responsible for multidrug resistance of TICs. NFAT2c has also been shown to enhance the TIC phenotypes of lung cancer by directly activating the expression of SOX2 ${ }^{33}$. Hence, it is likely that both the calcineurin/NFAT and Notch signaling pathways work coordinately to determine the stem celllike properties of NSCLC TICs.

Here, we also identified that $\alpha 2 \delta 1$ is an amenable therapeutic target for the treatment of lung cancer. Both silencing of $\alpha 2 \delta 1$ and treatment with $\alpha 2 \delta 1$ blocking antibody 1B50-1 could dramatically retard the tumorigenicity of NSCLC TICs, and the therapeutic effects of 1B50-1 on NSCLC were attributed to its ability to eradicate TICs in the tumors as shown by loss of serial transplantation capacity in NOD/SCID mice after treatment. Moreover, the therapeutic effects of 1B50-1 could be further augmented by the addition of carboplatin, supporting that a combinational therapy strategy in which TICs and tumor-mass constituent non-TICs are simultaneously targeted is required to achieve an efficient therapy outcome in solid tumors as demonstrated in many other studies ${ }^{34,35}$. Most importantly, $\alpha 2 \delta 1$ controls the expression of Notch, the therapy with $\alpha 2 \delta 1$ blocking antibody 1B50-1 hence targets the upstream of Notch signaling pathway, and therefore targeted therapy against $\alpha 2 \delta 1$ represents a more efficient way of therapy against TICs than those targeted Notch signaling pathway itself. Finally, this study, along with our previous work on hepatocellular carcinoma ${ }^{13}$, demonstrate that targeting the calcium channel $\alpha 2 \delta 1$ subunit with 1 B50-1 to prevent calcium influx is a novel cancer therapeutic strategy for targeted therapy against TICs.

In conclusion, the voltage-gated calcium channel $\alpha 2 \delta 1$ subunit is a novel functional marker and therapeutic target for NSCLC TICs. By using this marker, a subset of NSCLC TICs with stem cell-like properties, activated calcium and Notch signaling can be identified at the highest TIC frequency. Furthermore, $\alpha 2 \delta 1$ plays essential roles in the acquirement and subsequent maintenance of the stem cell-like properties of NSCLC TICs through $\mathrm{Ca}^{2+}$-NFAT mediated activation of Notch pathway. Most importantly, the mAb1B50-1, which blocks the function of $\alpha 2 \delta 1$, has remarkably therapeutic effects on NSCLC xenografts, providing a novel therapeutic approach targeting TICs for NSCLC patients.

\section{Materials and methods \\ Cell lines and clinical samples}

Human NSCLC cell lines A549, H520, H292, and H1299 were originated from the American Type Culture Collection (ATCC), and PC9, H157 and GLC82 cell lines were obtained from Deutsche Sammlung von Mikroorganismen und Zellkulturen (DSMZ). These cells were cultured in RPMI 1640 medium supplemented with 10\% fetal bovine serum (FBS), 100 units $/ \mathrm{mL}$ penicillin and $100 \mu \mathrm{g} / \mathrm{mL}$ streptomycin (Invitrogen, Grand Island, NY, USA) in a humidified $5 \% \mathrm{CO}_{2}$ incubator at $37^{\circ} \mathrm{C}$. The cell lines were 
authenticated using polymorphic short tandem repeat loci analysis and were cleared off mycoplasma contamination.

The primary NSCLC and matched normal tissue samples were collected from patients who had undergone complete resection (R0) at Peking University Cancer Hospital with written informed consent. Some of the fresh primary NSCLC tissues were minced and digested with DNase and collagenase/dispase, followed by transplantation into NOD/SCID mice to generate PDX model.

\section{Immunofluorescent staining and flow cytometry}

The single-cell suspension from NSCLC cell lines, tumor tissues were prepared according to our published proto$\mathrm{col}^{13}$, and were immediately incubated with the antibodies including mAb1B50-1 against $\alpha 2 \delta 1^{13}$ conjugated with fluorescein isothiocyanate (FITC) using BD Lightning conjugation kits (Expedeon Ltd., Cambridge, UK), CD24allophycocyanin (APC), CD90-APC, EpCAM-FITC and CD133-allophycoyanin (PE) obtained from Miltenyi Biotech GmbH (Bergisch Gladbach, Germany); and CD166-PE purchased from BD Biosciences (Bedford, MA, USA). To measure $\mathrm{Ca}^{2+}$ flux level, the cells were incubated with Fluo-4/AM (Invitrogen). After filtering through a $40-\mu \mathrm{m}$ nylon mesh, the viable and single cells were gated for analyses or sorting on a FACSAria II flow cytometer (BD Biosciences). The isotype control was used as reference and data were processed using FlowJo VX software.

\section{Tumorigenicity assay}

Female 5- to 6-week-old NOD/SCID mice (Vitalriver, Beijing, China) were used for the studies following protocols approved by the Peking University Cancer Hospital Animal Care and Use Committee. To test the tumorigenic potential, cells were suspended in $50 \mu \mathrm{l}$ of $1: 1 \mathrm{mix}$ of serum-free medium and Matrigel (BD Biosciences), and were injected s.c. into the armpit of mice. Tumor formation was monitored weekly. For the therapeutic assay, $2 \times 10^{6}$ cells per mouse were s.c. transplanted into the frank of mice. When all the tumors were visible, randomly separated groups of mice with comparable sizes of tumors were administered intraperitoneally (i.p.) with control vehicle, anti- $\alpha 2 \delta 1$ 1B50-1 mAb (800 $\mu \mathrm{g} / \mathrm{mice})$, carboplatin $(40 \mathrm{mg} /$ $\mathrm{kg}$ ), or the combination of both every other day. The tumors were measured in two dimensions with calipers and individual tumor volumes $(V)$ were calculated by the formula: $V=\left(\right.$ length $\mathrm{X}$ width $\left.{ }^{2}\right) / 2$. The sample sizes of animals were determined by calculations derived from our experience. No sample was excluded from the analyses, and the investigators were not blinded to the group allocation during the experiment and outcome assessment.

\section{Immunohistochemistry staining}

Sections of frozen NSCLC tissues were fixed with methanol for $30 \mathrm{~s}$. After blocking with 5\% non-fat milk in
PBS, slides were incubated with mAb1B50-1 at $4{ }^{\circ} \mathrm{C}$ overnight, followed by incubation with FITC-goat antimouse IgG. Nuclei were stained with 4,6-diamidino-2phenylindole dihydrochloride (DAPI; Polysciences, Warrington, PA) at $0.5 \mu \mathrm{g} / \mathrm{ml}$. Specimens were mounted in $90 \%$ glycerol/PBS containing $2.5 \%$ 1, 4-diazabicyclo $(2,2,2)$ octane. Slides were examined with a Leica SP5 confocal microscope (Leica, Wetzlar, Germany).

\section{RNA preparation and quantitative real-time PCR (qRT-PCR)}

Total RNA was extracted from the NSCLC cell lines and specimens using the RNAeasy Kit (Qiagen, Valencia, CA) according to the manufacturer's instruction. Complementary DNA was synthesized from $2 \mu$ g total RNA using the Multiscribe reverse transcriptase (Invitrogen, Grand Island, NY, USA). Quantitative PCR was performed using SYBR Green PCR Master Mix (Roche, Mannheim, Germany) on LightCycler ${ }^{\circledR} 480$ Real-Time PCR System (Roche). The glyceraldehyde-3-phosphate dehydrogenase (GAPDH) was used as an internal control. All primer sequences were listed in Supplementary Table 6 . The relative gene expression for each sample was calculated using the $2^{-\Delta \Delta \mathrm{Ct}}$ method $^{36}$.

\section{Western blot}

Cells were homogenized in radioimmunoprecipitation assay buffer supplemented with Complete Mini protease inhibitor cocktail, and phosphatase inhibitor cocktail (Roche, Mannheim, Germany). Equal amounts of protein were resolved by SDS-PAGE, and Western blot were carried out following standard protocols. The primary antibodies used were given in Supplementary Table 7. The HRP-conjugated secondary antibodies were purchased from Jackson ImmunoResearch Laboratories Inc. (West Grove, PA, USA). Immuno-complexes were visualized with ImmobilonTM Western Chemiluminescent HRP substrate (Millipore, Billerica, MA, USA).

\section{Apoptosis assay}

Apoptotic assay was performed in sorted $\alpha 2 \delta 1^{+}$and $\alpha 2 \delta 1^{-}$cells treated with carboplatin by FITC Annexin V Apoptosis Detection Kit (BD Biosciences) according to the manufacturer's instruction. In brief, suspension of treated cells was incubated with FITC Annexin V and propidium iodide for $20 \mathrm{~min}$ on ice, followed by analysis using BD Accuri ${ }^{\mathrm{TM}}$ C6 flow cytometer (BD Biosciences).

\section{Sphere formation assay}

Sphere formation assay was carried out in ultralow attachment 96-well plates (Corning Incorporated Life Sciences, Acton, MA, USA) by plating 100 cells per well in DMEM/F-12 serum-free medium containing B27, $20 \mathrm{ng} / \mathrm{ml}$ epidermal growth factor, $20 \mathrm{ng} / \mathrm{ml}$ basic fibroblast growth factor (Invitrogen), 1\% methylcellulose (Sigma-Aldrich, St. 
Louis, MO, USA). After 2-3 weeks of cultivation, the formed spheroids were counted under an Axio Observer A1 inverted microscope (Carl Zeiss Microscopy GmbH, Jena, Germany).

\section{Chromatin immunoprecipitation (ChIP) assay}

ChIP assay was done with the ChIP Assay kit (Millipore) following the vendor's instruction. In brief, cells were cross-linked with $1 \%$ formaldehyde at $37^{\circ} \mathrm{C}$ for $10 \mathrm{~min}$, followed by incubation with $150 \mathrm{mM}$ glycine for $5 \mathrm{~min}$ at room temperature to stop cross-linking. The cells were then harvested in SDS lysis buffer containing protease inhibitors. After the lysates were sonicated to shear the DNA into fragments of 200-1000 bps, immunoprecipitation with NFATc2 (Abcam) or nonspecific IgG was carried out overnight at $4{ }^{\circ} \mathrm{C}$. Protein G Sepharose (GE Healthcare, Little Chalfont, Buckinghamshire, UK) was added to the suspension to collect the antibody/NFATc2/ DNA complex, followed by rinsing with each of Low Salt Immune Complex Wash Buffer, High Salt Immune Complex Wash Buffer, LiCl Immune Complex Wash Buffer, and TE Buffer. The precipitated products were then eluted with elution buffer containing 1\% SDS, $0.1 \mathrm{~mol} / \mathrm{L} \mathrm{NaHCO}_{3}$, reversed the NFATc2/DNA crosslink with $5 \mathrm{~mol} / \mathrm{L} \mathrm{NaCl}$ at $65^{\circ} \mathrm{C}$ for $4 \mathrm{~h}$. The DNA was finally eluted, and purified by PCR Purification Kit from Qiagen. PCR was performed with primers listed in Supplementary Table 8.

\section{Vector construction}

The construction of $\alpha 2 \delta 1$ overexpression and shRNA lentiviral vectors, packaging of lentiviruses and infection of cells were the same as described in our previous paper $^{13}$. For luciferase reporter construction, the presumptive promoters of human NOTCH3 and ABCG2 containing the wild type NFATc2 binding consensus sequences $\left(5^{\prime}-\mathrm{TTTCC}-3^{\prime}\right)$ or the mutant sequences $\left(5^{\prime}\right.$ CAGCC- $3^{\prime}$ ) were synthesized by Sangon Biotech Co. (Shanghai, China) and subcloned into pGL3-basic vector.

\section{Luciferase reporter assay}

Luciferase reporter assay was done according to the manufacturer's protocol of Dual-Luciferase Reporter Assay system (Promega, Madison, USA). In brief, the cells were plated in 96-well culture plates and transfected with the indicated constructs using lipofectamine 3000 (Invitrogen). Luciferase activity was measured using the Lumat LB 9501 Luminometer (Berthold Technologies). Firefly luciferase values were normalized to Renilla luciferase value, yielding relative activities and are shown as mean values \pm SD.

\section{Statistics}

Data were analyzed using SPSS software (version 16.0, SPSS Inc., Chicago, IL), and the significance of differences was determined with a double-sided Student's $t$-test or one-way ANOVA unless otherwise specified. TIC frequencies were determined using the ELDA webtool at http://bioinf.wehi.edu.au/software/elda/ based on extreme limiting dilution analysis ${ }^{37}$. A $p \leq 0.05$ was considered statistically significant.

\section{Author contributions}

Y.M., X.Y., and Z.Z. designed and performed the experiments, analyzed the data and wrote the manuscript; W.Z. performed the experiments and analyzed the data; Y.Y. performed clinical study. All authors approved the manuscript.

\section{Funding statement}

This work was supported in part by the National Key Research and Development Program of China (Grant No. 2016YFA0500303), and the National Natural Science Foundation of China (Nos. 81730075, 81330051, 81772494, and 91529104), and Beijing Natural Science Foundation (No. 7192036).

\section{Ethics statement}

The patient tissues were obtained with written informed consent following tissue procurement protocols approved by the Ethics Committee of Peking University Cancer Hospital, and the study was performed in accordance with the Declaration of Helsinki.

\section{Conflict of interest}

W.Z. and Z.Z. own the patent related to the a2 $\delta 1$ antibody 1B50-1. All other authors declare no competing interests.

\section{Publisher's note}

Springer Nature remains neutral with regard to jurisdictional claims in published maps and institutional affiliations.

Supplementary information The online version contains supplementary material available at https://doi.org/10.1038/s41419-021-03522-0.

Received: 9 May 2020 Revised: 10 February 2021 Accepted: 12 February 2021

Published online: 11 March 2021

\section{References}

1. Siegel, R. L., Miller, K. D. \& Jemal, A. Cancer statistics, 2018. CA Cancer J. Clin. 68 7-30 (2018).

2. Chen, Z., Fillmore, C. M., Hammerman, P. S., Kim, C. F. \& Wong, K. K. Non-smallcell lung cancers: a heterogeneous set of diseases. Nat. Rev. Cancer 14, 535-546 (2014)

3. Clarke, M. F. et al. Cancer stem cells-perspectives on current status and future directions: AACR Workshop on cancer stem cells. Cancer Res. 66, 9339-9344 (2006).

4. Pardal, R., Clarke, M. F. \& Morrison, S. J. Applying the principles of stem-cell biology to cancer. Nat. Rev. Cancer 3, 895-902 (2003).

5. Clevers, $H$. The cancer stem cell: premises, promises and challenges. Nat. Med. 17, 313-319 (2011)

6. Visvader, J. E. \& Lindeman, G. J. Cancer stem cells: current status and evolving complexities. Cell Stem Cell 10, 717-728 (2012).

7. Frank, N. Y., Schatton, T. \& Frank, M. H. The therapeutic promise of the cancer stem cell concept. J. Clin. Invest. 120, 41-50 (2010).

8. Eramo, A. et al. Identification and expansion of the tumorigenic lung cancer stem cell population. Cell Death Differ. 15, 504-514 (2008).

9. Leung, E. L. et al. Non-small cell lung cancer cells expressing CD44 are enriched for stem cell-like properties. PLOS ONE 5, e14062 (2010).

10. Zhang Wen, C. et al. Glycine decarboxylase activity drives non-small cell lung cancer tumor-initiating cells and tumorigenesis. Cell 148, 259-272 (2012).

11. Tirino, V. et al. The role of CD133 in the identification and characterisation of tumour-initiating cells in non-small-cell lung cancer. Eur. J. Cardiothorac. Surg. 36, 446-453 (2009). 
12. Zhang, Y. et al. NOTCH1 signaling regulates self-renewal and platinum chemoresistance of cancer stem-like cells in human non-small cell lung cancer. Cancer Res. 77, 3082-3091 (2017).

13. Zhao, W. et al. 1B50-1, a mAb raised against recurrent tumor cells, targets liver tumor-initiating cells by binding to the calcium channel a2 $\delta 1$ subunit. Cancer Cell. 23, 541-556 (2013).

14. Yu, J. et al. Mechanistic exploration of cancer stem cell marker voltagedependent calcium channel a2 $\delta 1$ subunit-mediated chemotherapy resistance in small-cell lung cancer. Clin. Cancer Res. 24, 2148-2158 (2018).

15. Sun, $\mathrm{C}$. et al. Central role of IP3R2-mediated $\mathrm{Ca}(2+)$ oscillation in self-renewal of liver cancer stem cells elucidated by high-signal ER sensor. Cell Death Dis. 10, 396 (2019).

16. Yasuda, T. et al. Auxiliary subunit regulation of high-voltage activated calcium channels expressed in mammalian cells. Eur. J. Neurosci. 20, 1-13 (2004).

17. Campiglio, M. \& Flucher, B. E. The role of auxiliary subunits for the functional diversity of voltage-gated calcium channels. J. Cell Physiol. 230, 2019-2031 (2015).

18. Eroglu, C. et al. Gabapentin receptor a $2 \delta 1$ is a neuronal thrombospondin receptor responsible for excitatory CNS synaptogenesis. Cell 139, 380-392 (2009).

19. Clapham, D. E. Calcium signaling. Cell 131, 1047-1058 (2007).

20. Cheng, H. P., Wei, S., Wei, L. P. \& Verkhratsky, A. Calcium signaling in physiology and pathophysiology. Acta Pharm. Sin. 27, 767-772 (2006).

21. Mancini, M. \& Toker, A. NFAT proteins: emerging roles in cancer progression Nat. Rev. Cancer 9, 810-820 (2009).

22. Khalilimeybodi, A., Daneshmehr, A. \& Sharif Kashani, B. Ca2+-dependent calcineurin/NFAT signaling in beta-adrenergic-induced cardiac hypertrophy. Gen. Physiol. Biophys. 37, 41-56 (2018).

23. Bertolini, G. et al. Highly tumorigenic lung cancer CD133+ cells display stemlike features and are spared by cisplatin treatment. Proc. Natl Acad. Sci. USA 106, 16281-16286 (2009).

24. Zheng, $Y$. et al. A rare population of CD24(+)ITGB4(+)Notch(hi) cells drives tumor propagation in NSCLC and requires Notch3 for self-renewal. Cancer Cell. 24, 59-74 (2013).
25. Pannuti, A. et al. Targeting Notch to target cancer stem cells. Clin. Cancer Res. 16, 3141-3152 (2010)

26. Tang, K. H. et al. A CD90(+) tumor-initiating cell population with an aggressive signature and metastatic capacity in esophageal cancer. Cancer Res. 73, 2322-2332 (2013)

27. Han, H. et al. PBX3 is targeted by multiple miRNAs and is essential for liver tumour-initiating cells. Nat. Commun. 6, 8271 (2015).

28. Bauer, C. S., Tran-Van-Minh, A., Kadurin, I. \& Dolphin, A. C. A new look at calcium channel a2 $\delta$ subunits. Curr. Opin. Neurobiol. 20, 563-571 (2010).

29. Davies, A. et al. The a $2 \delta$ subunits of voltage-gated calcium channels form GPIanchored proteins, a posttranslational modification essential for function. Proc. Natl Acad. Sci. USA 107, 1654-1659 (2010).

30. Ohashi, S. et al. NOTCH1 and NOTCH3 coordinate esophageal squamous differentiation through a CSL-dependent transcriptional network. Gastroenterology 139, 2113-2123 (2010).

31. Mammucari, C. et al. Integration of Notch 1 and calcineurin/NFAT signaling pathways in keratinocyte growth and differentiation control. Dev. Cell 8 , 665-676 (2005).

32. Hassan, K. A. et al. Notch pathway activity identifies cells with cancer stem celllike properties and correlates with worse survival in lung adenocarcinoma. Clin. Cancer Res. 19, 1972-1980 (2013).

33. Xiao, Z. J. et al. NFATC2 enhances tumor-initiating phenotypes through the NFATC2/SOX2/ALDH axis in lung adenocarcinoma. Elife 6, e26733 (2017).

34. Sainz, B. \& Heeschen, C. Standing out from the crowd: cancer stem cells in hepatocellular carcinoma. Cancer Cell. 23, 431-433 (2013).

35. Clara, J. A., Monge, C., Yang, Y. \& Takebe, N. Targeting signalling pathways and the immune microenvironment of cancer stem cells - a clinical update. Nat. Rev. Clin. Oncol. 17, 204-232 (2020).

36. Pfaffl, M. W. A new mathematical model for relative quantification in real-time RT-PCR. Nucleic Acids Res. 29, e45 (2001).

37. Hu, Y. \& Smyth, G. K. ELDA: extreme limiting dilution analysis for comparing depleted and enriched populations in stem cell and other assays. J. Immunol. Methods 347, 70-78 (2009). 